\title{
PRESCRIBING PATTERNS FOR INPATIENTS WITH SCHIZOPHRENIA SPECTRUM DISORDERS IN A PSYCHIATRIC HOSPITAL IN SLOVENIA: RESULTS OF 16-MONTH PROSPECTIVE, NON-INTERVENTIONAL CLINICAL RESEARCH
}

\author{
Cvetka Bačar Bole ${ }^{1}$, Mitja Pišlar², Aleš Mrhar ${ }^{2}$ \& Rok Tavčar ${ }^{3}$ \\ ${ }^{I}$ Psychiatric Hospital Idrija, Idrija, Slovenia \\ ${ }^{2}$ Faculty of Pharmacy, University of Ljubljana, Ljubljana, Slovenia \\ ${ }^{3}$ University Psychiatric Clinic Ljubljana, Ljubljana, Slovenia
}

received: 7.11.2016;

revised: 7.3.2017;

accepted: 19.4.2017

\begin{abstract}
SUMMARY
Background: In Slovenia, there has been no evidence about the prescribing patterns for inpatients with psychotic disorders. The research aims to analyze drug utilization patterns for inpatients with psychotic disorder that are coded as F20-F29 according to International Classification of Diseases (ICD) $10^{\text {th }}$ revision (schizophrenia spectrum disorders).

Subjects and methods: Prospective research was conducted at the Psychiatric Hospital Idrija. The medical records of the inpatients admitted over a 12-month period were collected from the beginning to the end of their hospitalization.

Results: A total of 311 inpatients with 446 hospitalizations were included, producing a total of 3954 medication prescriptions. Medications prescribed pro re nata (the use of as needed) were also taken into account. Antipsychotics ( $N=1149$, 43\% of prescriptions) were the most often prescribed medications, followed by anxiolytics, antiparkinsonians, antidepressants, mood stabilizers and cardiovascular drugs. A total of 256 (82\%) inpatients received at least one pro re nata medication. It was observed that the studied population was treated with one antipsychotic on 27 percent of prescriptions.

Conclusions: Inpatients with schizophrenia spectrum disorders were exposed to a large number of different drugs. They were not received only psychotropic drugs but also other medications. With the knowledge about medications the implementation of clinical pharmacy services to the psychiatrists would significantly improve medication of inpatients with psychotic disorders and polypharmacotherapy.
\end{abstract}

Key words: inpatients - schizophrenia - prescribing patterns

$* * * * *$

\section{INTRODUCTION}

Previously, the primary focus in treating psychotic disorders was on controlling positive symptoms with conventional, first-generation antipsychotics (FGA). These agents have poor efficacy on negative symptoms and some serious adverse reactions (Stahl 2009, Parkpoor \& Agius 2014). Today, psychotic disorders treatment is more complex, with more comprehensive options now aiming to provide relief in all symptom domains, improve compliance and prevent relapse, reduce adverse reactions and improve functional outcomes (Lehman et al. 2004). The increasing use of atypical, second-generation antipsychotics (SGA) reduced the mean duration of admission (Chong et al. 2010).

Patients with psychotic disorders often require longterm, highly intensive treatment and care. Individuals with schizophrenia have a $20 \%$ shorter life expectancy then the population at large and greater vulnerability to diabetes, coronary heart disease, hypertension and emphysema (Hennekens et al. 2005, Newcomer \& Haupt 2006). Consequently, they are usually receiving a large number of different medications (polypharmaco- therapy). Moreover, the lifestyles of people with psychotic disorders often associated with alcohol and street drugs use, poor dietary habits, obesity and high rates of smoking, contribute to several illnesses (Covell et al. 2006).

Some of antipsychotics have been associated with weight gain, the onset of diabetes, increases in lipid levels, changes of the electrocardiogram, prolactin elevation, cataract formation, movement disorders and sexual dysfunction (Stahl 2009). Polypharmacotherapy with antipsychotics may further increase the risk of adverse reactions (Weiden et al. 1998).

Some of the previous studies on prescribing practices in psychiatric hospitals in Europe examined only the patterns of psychotropic prescribing (Jordanova et al. 2011, Davids et al. 2006, Rittmannsberger et al. 1999, Szkultecka-Dębek et al. 2016).

In Slovenia, there has been no evidence about the prescribing patterns for psychiatric inpatients. The research is conducted to quantify all drug utilization patterns for inpatients with psychotic disorder that are coded as F20-F29 according to International Classification of Diseases (ICD) 10th revision (schizophrenia spectrum disorders / SSD). 


\section{SUBJECTS AND METHODS}

\section{Study cohort}

The Psychiatric Hospital Idrija (PBI) is one of the six psychiatric hospitals (one of them is university clinic) in Slovenia. PBI carries out its activities in the area with over than 308,000 inhabitants. It is peripherally located on the West of the country and as the second largest Slovenian psychiatric hospital generally reflects the organization of inpatients mental health care in Slovenia. During the period of the research the hospital had about 170 beds for acute and long-term inpatients.

Eligible inpatients met the following inclusion criteria: psychotic disorders that are coded as F20-F29 according to International Classification of Diseases (ICD) 10th revision and aged between 18 and 65 years. The exclusion criteria were as follows: inpatients with liver and/or kidney diseases and pregnant women. Data were collected from inpatients admitted to PBI over a 12-month period (from December 1, 2009 to November $30,2010)$. Inpatients were monitored from the beginning to the end of their hospitalization; the last one was discharged in March 2011, so the research period was 16 months. No patient dropped out from the study. The study has been approved by the National Medical Ethics Committee of the Republic of Slovenia.

\section{Data collection}

Documented inpatient's characteristics were sex, age, body mass index, smoking status, coffee and alcohol consumption, marital status, diagnoses and number and length of hospitalization. All medications prescribed in the ward were recorded. All data were recorded in special forms prepared for the purpose of the research.

\section{Statistical analysis}

Statistical analysis was done using the IBM SPSS statistics 20 software package (IBM SPSS, Chicago, IL, USA). Frequencies (percentages) were used to describe categorical variables and for descriptive purposes; variables were presented as arithmetic means or medians.

\section{RESULTS}

\section{Inpatient's characteristics}

A total of 311 inpatients were included in the research. The mean age was 42 years $(\min =19, \max =65)$ and the mean body mass index was $27(\min =16$, max $=60)$. 69 percent of the inpatients $(\mathrm{N}=213)$ were smokers ( $76 \%$ of males vs. $58 \%$ of females), 95 percent $(\mathrm{N}=294)$ consumed coffee $(96 \%$ of males vs. $92 \%$ of females), 53 percent consumed alcohol ( $72 \%$ of males vs. $28 \%$ of females) and 77 percent of the inpatients were single ( $89 \%$ of males vs. $62 \%$ of females).

47 percent of the inpatients were hospitalized due to one of the types of schizophrenia. Paranoid schizophrenia (F20.0) was predominant diagnosis ( $\mathrm{N}=98,32 \%, 36 \%$ of males vs. $25 \%$ of females), followed by acute and transient psychotic disorders (30\%). Catatonic schizophrenia and delusional disorder have not been diagnosed.

\section{Hospitalization's characteristics}

There were 446 hospitalizations. In the research period, the majority of the inpatients $(73 \%)$ were hospitalized once, 17 percent twice and 10 percent three times or more (one inpatient was hospitalized seven times). 23 percent of the inpatients were hospitalized for the first time.

On average, inpatients stayed at the ward 44 days ( median $=34, \min =1, \max =286$ ).

\section{Medication prescriptions}

A total of 3954 medication prescriptions were analyzed. Medications prescribed pro re nata (the use of as needed) are taken into account, but these drugs were analyzed separately. The most often prescribed drug was antiparkinsonian biperiden $(\mathrm{N}=231,9 \%)$, followed by anxiolytic diazepam ( $\mathrm{N}=177,7 \%)$. According to the Anatomical Therapeutic Chemical classification index (ATC), antipsychotics were prescribed most frequently, followed by anxiolytics, antiparkinsonians, antidepressants, antiepileptics (mood stabilizers) and cardiovascular drugs (Figure 1).

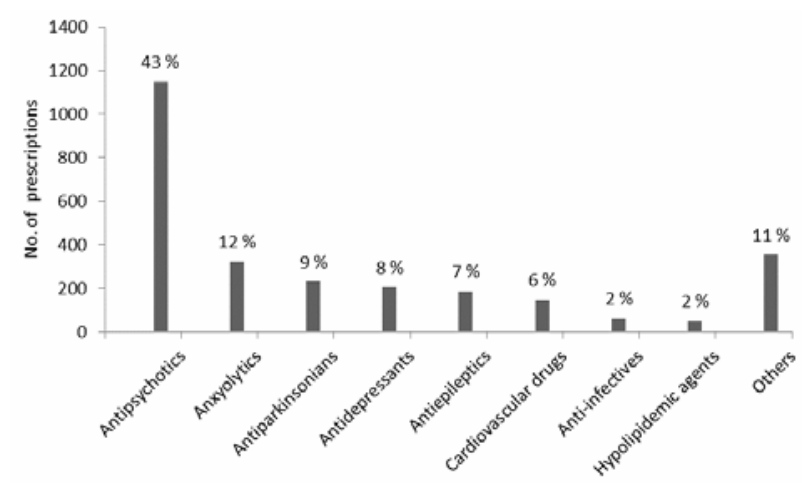

Figure 1. Summary of prescribing medications (drugs prescribed pro re nata are not taken into account)

\section{Antipsychotics}

Among antipsychotics, the most frequently prescribed were fluphenazine $(\mathrm{N}=157,14 \%)$, olanzapine $(\mathrm{N}=155,14 \%)$, quetiapine $(\mathrm{N}=135,12 \%)$, haloperidol $(\mathrm{N}=131,11 \%)$ and clozapine $(\mathrm{N}=121,11 \%)$. Table 1 shows the prescribing daily doses (PDD) of antipsychotics. The relationship between the number of antipsychotics and the number of prescriptions is given in Table 2. The dual medications of antipsychotics are presented in Table 3 . 
Table 1. The prescribed daily dose of antipsychotic (PDD) and comparison of the average maintenance dose per day for a drug used for its main indication in adults (DDD)

\begin{tabular}{lcccc}
\hline Antipsychotic & DDD $(\mathrm{mg})$ & $\begin{array}{c}\text { PDD mean } \\
(\mathrm{SD})(\mathrm{mg})\end{array}$ & $\begin{array}{c}\text { PDD median } \\
(\mathrm{min} / \mathrm{max})(\mathrm{mg})\end{array}$ & $\begin{array}{c}\text { Average length of time of } \\
\text { antipsychotic use }(\mathrm{min} / \mathrm{max})(\mathrm{day})\end{array}$ \\
\hline Amisulpride & 400 & $388(244)$ & $324(800 / 100)$ & $23(4 / 210)$ \\
Aripiprazole & 15 & $16(6)$ & $15(30 / 5)$ & $35(2 / 204)$ \\
Clozapine & 300 & $203(119)$ & $192(600 / 15)$ & $44(3 / 279)$ \\
Flupenthixol & 6 & $9(4)$ & $8(18 / 3)$ & $39(6 / 130)$ \\
Fluphenazine & 10 & $16(8)$ & $15(39 / 3)$ & $35(2 / 162)$ \\
Haloperidol & 8 & $19(8)$ & $17(43 / 2)$ & $31(1 / 187)$ \\
Levomepromazine & 300 & $142(142)$ & $100(300 / 25)$ & $21(7 / 38)$ \\
Lithium & $/$ & $903(120)$ & $900(1164 / 750)$ & $39(6 / 97)$ \\
Lithium R & $/$ & $907(108)$ & $900(1286 / 900)$ & $37(3 / 79)$ \\
Olanzapine & 10 & $15(4)$ & $15(24 / 5)$ & $25(1 / 82)$ \\
Paliperidone & 6 & $7(2)$ & $7(12 / 3)$ & $38(2 / 204)$ \\
Promazine & 300 & $175(122)$ & $150(419 / 25)$ & $23(2 / 133)$ \\
Quetiapine & $286(223)$ & $217(800 / 25)$ & $30(2 / 106)$ \\
Quetiapine SR & 400 & $352(206)$ & $318(800 / 50)$ & $30(2 / 186)$ \\
Risperidone & 400 & $4(2)$ & $4(7 / 1)$ & $15(3 / 33)$ \\
Sulpiride & 5 & $182(121)$ & $100(371 / 100)$ & $44(8 / 94)$ \\
Ziprasidone & 800 & $132(31)$ & $136(160 / 71)$ & $35(9 / 72)$ \\
Zuclopenthixol & 80 & $26(12)$ & $20(51 / 13)$ & \\
\hline
\end{tabular}

DDD - maintenance dose per day for a drug used for its main indication in adults; PDD - prescribed daily dose of antipsychotic;

$\mathrm{R}$ - controlled release; $\mathrm{SD}$ - standard deviation; $\mathrm{SR}$ - slow (extended)-release

Table 3. Dual medications of antipsychotics

\begin{tabular}{|c|c|c|c|c|c|c|c|c|c|c|c|c|c|c|c|c|c|c|}
\hline Antipsychotic & 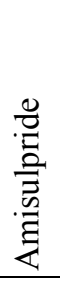 & 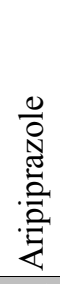 & 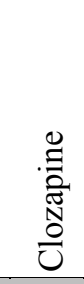 & 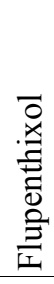 & 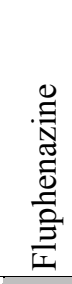 & 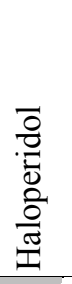 & 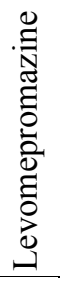 & 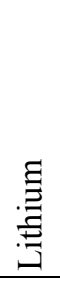 & 㖊 & 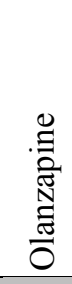 & 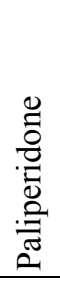 & 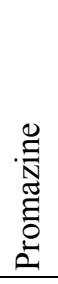 & 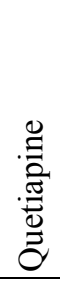 & 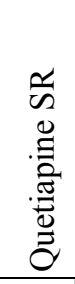 & 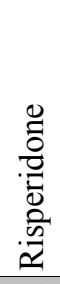 & 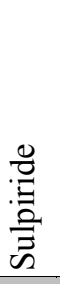 & 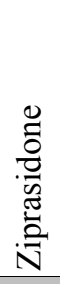 & 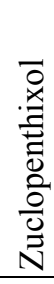 \\
\hline Amisulpride & 1 & 6 & 41 & 0 & 32 & 18 & 0 & 0 & 0 & 4 & 0 & 0 & 0 & 0 & 3 & 1 & 1 & 0 \\
\hline Aripiprazole & 6 & l & 91 & 30 & 9 & 23 & 0 & 0 & 21 & 28 & 6 & 0 & 36 & 33 & 38 & 0 & 0 & 3 \\
\hline Clozapine & 41 & 91 & / & 27 & 441 & 227 & 0 & 49 & 31 & 46 & 16 & 7 & 23 & 26 & 74 & 2 & 72 & 17 \\
\hline Flupenthixol & 0 & 30 & 27 & / & 2 & 1 & 0 & 0 & 3 & 4 & 0 & 3 & 0 & 5 & 0 & 6 & 3 & 0 \\
\hline Fluphenazine & 32 & 9 & 441 & 2 & / & 45 & 6 & 25 & 13 & 201 & 1 & 54 & 85 & 112 & 57 & 5 & 86 & 0 \\
\hline Haloperidol & 18 & 23 & 227 & 1 & 45 & l & 3 & 35 & 30 & 338 & 19 & 63 & 67 & 83 & 20 & 0 & 7 & 12 \\
\hline Levomepromazine & 0 & 0 & 0 & 0 & 6 & 3 & / & 0 & 0 & 0 & 0 & 3 & 4 & 0 & 0 & 0 & 0 & 3 \\
\hline Lithium & 0 & 0 & 49 & 0 & 25 & 35 & 0 & l & 4 & 0 & 0 & 5 & 6 & 29 & 13 & 0 & 18 & 0 \\
\hline Lithium R & 0 & 21 & 31 & 3 & 13 & 30 & 0 & 4 & l & 33 & 0 & 3 & 13 & 34 & 27 & 0 & 15 & 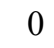 \\
\hline Olanzapine & 4 & 28 & 46 & 4 & 201 & 338 & 0 & 0 & 33 & l & 30 & 18 & 14 & 14 & 55 & 0 & 3 & 11 \\
\hline Paliperidone & 0 & 6 & 16 & 0 & 1 & 19 & 0 & 0 & 0 & 30 & l & 7 & 13 & 1 & 21 & 1 & 0 & 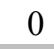 \\
\hline Promazine & 0 & 0 & 7 & 3 & 54 & 63 & 3 & 5 & 3 & 18 & 7 & / & 15 & 7 & 6 & 1 & 0 & 1 \\
\hline Quetiapine & 0 & 36 & 23 & 0 & 85 & 67 & 4 & 6 & 13 & 14 & 13 & 15 & l & 21 & 24 & 0 & 0 & 0 \\
\hline Quetiapine SR & 0 & 33 & 26 & 5 & 112 & 83 & 0 & 29 & 34 & 14 & 1 & 7 & 21 & / & 51 & 1 & 0 & 13 \\
\hline Risperidone & 3 & 38 & 74 & 0 & 57 & 20 & 0 & 13 & 27 & 55 & 21 & 6 & 24 & 51 & $r$ & 0 & 0 & 0 \\
\hline Sulpiride & 1 & 0 & 2 & 6 & 5 & 0 & 0 & 0 & 0 & 0 & 1 & 1 & 0 & 1 & 0 & l & 0 & 0 \\
\hline Ziprasidone & 1 & 0 & 72 & 3 & 86 & 7 & 0 & 18 & 15 & 3 & 0 & 0 & 0 & 0 & 0 & 0 & l & 0 \\
\hline Zuclopenthixol & 0 & 3 & 17 & 0 & 0 & 12 & 3 & 0 & 0 & 11 & 0 & 1 & 0 & 13 & 0 & 0 & 0 & \\
\hline
\end{tabular}

$\mathrm{R}$ - controlled release; $\quad \mathrm{SR}$ - slow (extended)-release; Shaded - avoid combination; italic - the most frequent combinations 
Table 2. Number of antipsychotics in prescriptions

\begin{tabular}{ccc}
\hline $\begin{array}{l}\text { No. of } \\
\text { antipsychotics }\end{array}$ & $\begin{array}{c}\text { No. of } \\
\text { prescriptions }\end{array}$ & $\begin{array}{c}\text { Percentage of } \\
\text { prescriptions }\end{array}$ \\
\hline 0 & 28 & $<1$ \\
1 & 1066 & 27 \\
2 & 1847 & 47 \\
3 & 876 & 22 \\
4 & 128 & 3 \\
5 & 8 & $<0.2$ \\
6 & 1 & $<0.1$ \\
Total & 3954 & 100 \\
\hline
\end{tabular}

\section{Anxiolytics}

Among 322 prescriptions of anxiolytics for regular use (not pro re nata), diazepam $(\mathrm{N}=177,55 \%)$, lorazepam $(\mathrm{N}=94,29 \%)$ and alprazolam $(\mathrm{N}=46,14 \%)$ were the most often prescribed.

\section{Antiparkinsonians}

Only two antiparkinsonians were prescribed: biperiden and pramipexole. Biperiden showed a high number of prescriptions $(\mathrm{N}=231)$ and pramipexole had only one prescription.

\section{Antidepressants}

Sertraline, mirtazapine and escitalopram were the most frequently prescribed antidepressants (Table 4).

Table 4. Summary of prescribing antidepressants

\begin{tabular}{lcc}
\hline Antidepressants & $\begin{array}{c}\text { No. of } \\
\text { prescriptions }\end{array}$ & Percentage \\
\hline Sertraline & 65 & 32 \\
Mirtazapine & 28 & 14 \\
Escitalopram & 23 & 11 \\
Venlafaxine & 18 & 9 \\
Paroxetine & 14 & 7 \\
Fluoxetine & 13 & 6 \\
Duloxetine & 12 & 6 \\
Citalopram & 8 & 4 \\
Bupropion & 8 & 4 \\
Clomipramine & 5 & 2 \\
Tianeptine & 5 & 2 \\
Agomelatin & 4 & 2 \\
Amitriptyline & 1 & 0.5 \\
Maprotiline & 1 & 0.5 \\
Total & 205 & 100 \\
\hline
\end{tabular}

\section{Antiepileptics (mood stabilizers)}

Among antiepileptics, valproic acid $(\mathrm{N}=110,60 \%)$, lamotrigine $(\mathrm{N}=45,24 \%)$ and carbamazepine $(\mathrm{N}=16$, $9 \%$ ) were the most frequently prescribed.

\section{Medications prescribed pro re nata}

We take into account only medications that have been prescribed pro re nata and also administered. A total of $256(82 \%)$ inpatients received medications prescribed pro re nata. 22 percent $(\mathrm{N}=55)$ of them received two medications, 16 percent $(\mathrm{N}=42)$ of them received one medication but some inpatients constantly received a greater number of different medications prescribed pro re nata. The most frequently drugs prescribed pro re nata were anxiolytics $(\mathrm{N}=161,63 \%)$, hypnotics $(\mathrm{N}=152,59 \%)$, analgesics $(\mathrm{N}=113,44 \%)$, antipsychotics $(\mathrm{N}=109,43 \%)$, laxatives $(\mathrm{N}=91,36 \%)$ and antiparkinsonians $(\mathrm{N}=61,24 \%)$.

\section{DISCUSSION}

The crucial differences between previous research on the pharmacological medication of psychiatric inpatients and our research are as follows: the previous research examined only the patterns of psychotropic prescribing for inpatients with different psychiatric disorders, our research examined the prescribing patterns of all medications for inpatients with specific disorders coded as F20-F29, some of the previous research were carried out on the certain day and they were retrospective, our 16-month research was prospective, observational and non-interventional (Jordanova et al. 2011, Rittmannsberger et al. 1999). A limitation of this research is its monocentric character, nevertheless the number of included inpatients $(\mathrm{N}=311)$ was high enough to get representative data, especially for Slovenia.

In the observed population, the portion of males was higher than that of females (58\% vs. $42 \%)$. Inpatients were smokers, singles, had BMI in the overweight range and the majority of them consumed coffee and alcohol, respectively (Covell et al. 2006). In the research period, due to the frequent relapse of SSD, almost one third of the inpatients $(27 \%)$ were hospitalized several times.

\section{Use of medications}

Our inpatients were exposed to a polypharmacotherapy. A considerable amount of prescribed medications was an antiholinergic antiparkinsonian biperiden as its role is to mitigate the adverse reactions (extrapyramidal symptoms) of FGA (Sweetman 2007). Concomitant use of two or more antiholinergic drugs may increase the risks associated with antiholinergic activity. Such effects may include, dry mouth, dry eyes, blurred vision, urinary retention, constipation and cognitive impairment (Stockley 2002).

We found $322(12 \%)$ prescriptions of anxiolytics, mostly diazepam, lorazepam and alprazolam, prescribed for regular use. 63 percent of medications prescribed pro re nata were benzodiazepines. In the Australian research of use pro re nata medications in acute inpatients found that the second highest rate of prescription of regular medications were benzodiazepines $(23 \%)$, with 
diazepam accounting for $18 \%$ of the total prescribed regular prescriptions (Stein-Parbury et al. 2008). In psychiatric hospitals in Eastern Europe (Albania, Croatia, Romania and Serbia) was also very high prevalence of use of benzodiazepines (Jordanova et al. 2011). Anxiolytics (benzodiazepines) are used for the treatment of anxiety and its related symptoms such as emotional, neurotic and sleep disorders. Although these drugs were prescribed pro re nata inpatients used them regularly for more than two weeks, which constitutes a considerable risk of tolerance and dependence, accompanied with withdrawal and rebound syndromes (Stahl 2009, O’Brien 2005).

In combination with antipsychotics, antidepressants were often used to treat negative psychotic symptoms. A total of 205 prescriptions of antidepressants were recorded (Table 4). Some combinations of antipsychotics and antidepressants should be avoided. For example, the concomitant use of highest risk QTc-prolonging antidepressants (e.g., citalopram, escitalopram, fluoxetine) with any other QTc-prolonging agent (e.g., flupentixol, paliperidone, quetiapine, sulpiride, ziprazidone, zuclopentixol) should be avoided. Many such combinations are listed contraindications for these drugs. Concomitant use is expected to substantially increase the risk for serious toxicities, including the development of torsades de pointes (TdP) or other significant ventricular tachyarrhythmias. Patients with other risk factors present (e.g., older age, female sex, bradycardia, hypokalemia, hypomagnesemia, heart disease and higher drug concentrations) would be at an even higher risk for these potentially life-threatening toxicities (Drew et al. 2010).

The inpatients were also given non-psychotropic medications $(21 \%$ of the total prescribed regular prescriptions): cardiovascular drugs, hypolipidemic drugs, anti-infectives and others (Figure 1) (Stahl 2009, Newcomer \& Haupt 2006, Hennekens et al. 2005). The use of some medications is probably justified since they reduce or eliminate adverse reactions of antipsychotics (Covell et al. 2006, De Hert et al. 2006).

It was anticipated that antipsychotics would be the most frequently used drugs for inpatients with SSD (Figure 1).

Guidelines of the World Federation of Societies of Biological Psychiatry give priority to SGA over FGA (Hasan et al. 2012). The reasons for a relatively high percentage $(41 \%)$ of prescribed FGA (flupenthixol, fluphenazine, haloperidol, levomepromazine, promazine, sulpiride and zuclopenthixol) lie in the fact that they represent a traditional, low-priced alternative to SGA (amisulpride, aripiprazole, clozapine, olanzapine, paliperidone, quetiapine, risperidone and ziprasidone), they are available in different dosage forms and, finally, they exhibit effective sedation in restless and often aggressive inpatients (Stahl 2009, Parkpoor \& Agius 2014). Almost at the same time, even 60 percent of the inpatients with psychosis in Eastern Europe received FGA (Jordanova et al. 2011).
82 percent of the acute and long-term inpatients received medications prescribed pro re nata. In the Australian research, 97 percent of acute inpatients received medications prescribed pro re nata (SteinParbury et al. 2008). There is a high risk of polypharmacotherapy and drug interactions, especially when pro re nata medications are different than those regularly prescribed. It was found that in a large number of the inpatients $(\mathrm{N}=109,35 \%)$ antipsychotics in different dosage forms were prescribed pro re nata: a) intramuscular injections - haloperidol $(\mathrm{N}=35,14 \%)$, aripiprazole $(\mathrm{N}=4,2 \%)$ and zuclopenthixol $(\mathrm{N}=1,0.5 \%), \mathrm{b})$ tablets olanzapine $(\mathrm{N}=27,11 \%)$, haloperidol $(\mathrm{N}=18,7 \%)$, clozapine $(\mathrm{N}=17,7 \%)$, risperidone $(\mathrm{N}=13,5 \%)$, fluphenazine $(\mathrm{N}=7,3 \%)$, promazine $(\mathrm{N}=7,3 \%)$ and quetiapine $(\mathrm{N}=7,3 \%)$ and c) solution - haloperidol $(\mathrm{N}=38,15 \%)$. In the Australian research, the second most frequently administered pro re nata medications (18\%) were FGA (Stein-Parbury et al. 2008).

Amisulpride, clozapine, levomepromazine, promazine, quetiapine, risperidone, sulpiride and zuclopenthixol were prescribed in too low doses (Table 1). The differences between the average maintenance dose per day for a drug used for its main indication in adults (DDD) and the mean prescribed daily dose (PDD) are in some cases substantial (Table 1). These observations imply that dosing of antipsychotics is not optimal. The same conclusions have been drawn in an Italian district (Bolcato et al. 2014). Comparing PDD at the first introduction of antipsychotic (data are not presented) with DDD we found that antipsychotic therapy was started with smaller doses which was followed by larger doses on the basis of titration (the differences between min PDD and max PDD are very large for the majority of antipsychotics). Based on the number of hospitalizations, olanzapine $(\mathrm{N}=149)$, fluphenazine $(\mathrm{N}=148)$, quetiapine $(\mathrm{N}=132)$, haloperidol $(\mathrm{N}=122)$, clozapine $(\mathrm{N}=115)$ and risperidone $(\mathrm{N}=109)$ were the most frequently prescribed antipsychotics. The duration of therapy with antipsychotics oscillates from only few days to the defined number of months, with clozapine which is used at the farthest (Table 1).

Crucial information (Table 2) was also the number of prescribed antipsychotics per inpatient. It was observed that studied population was treated with one antipsychotic on 27 percent of prescriptions. Two and three antipsychotics were concomitantly prescribed on 47 percent and 22 percent of prescription, respectively. It was found that more than three antipsychotics were prescribed concomitantly on 4 percent of prescription. This is again not in agreement with recommendations of the British Association for Psychopharmacology where it is clearly stated that combinations of antipsychotics should be avoided except in the case of switching (Barnes 2011). During the observational period, at least one switch of antipsychotic was recorded in 37 percent of the inpatients (abrupt switch was recorded in 31 percent). In specific cases, it is possible that multiple 
antipsychotics were used concurrently during the switching process. It was also observed that in less than 1 percent of prescriptions $(\mathrm{N}=28)$ antipsychotics were not prescribed. These cases may confirm the statement of some authors claiming that a non-pharmacological approach may be suitable for some specific groups of patients with schizophrenia (Matei et al. 2014). In Austrian psychiatric clinics, it was observed that more than half the schizophrenic inpatients are prescribed more than one antipsychotic and from 1 to 12 percent antipsychotics were not prescribed (Rittmannsberger et al. 1999).

Table 3 shows all dual medications of antipsychotics that may not be appropriate as they represent a potential risk of interaction (Canales et al. 2001) and also Guidelines of the World Federation of Societies of Biological Psychiatry recommend the use of only one antipsychotic (Hasan et al. 2012). Some combinations of antipsychotic should be avoided, for example, the concomitant use of amisulpride with other antipsychotics (Table 3). The most common prescribed combinations of antipsychotics were clozapine/fluphenazine ( $\mathrm{N}=441,11 \%)$, haloperidol/olanzapine ( $\mathrm{N}=338,9 \%)$, haloperidol/clozapine $(\mathrm{N}=227,6 \%)$, olanzapine/fluphenazine $(\mathrm{N}=201,5 \%)$ and quetiapine/fluphenazine $(\mathrm{N}=197,5 \%)$.

Dual medications of long acting with short acting antipsychotics were most often prescribed for a limited period where switching antipsychotics was indicated: fluphenazine decanoate/fluphenazine $(\mathrm{N}=280,7 \%)$, fluphenazine decanoate/clozapine $(\mathrm{N}=163,4 \%)$, fluphenazine decanoate/quetiapine $(\mathrm{N}=121,3 \%)$, flupenthixol decanoate/clozapine $(\mathrm{N}=120,3 \%)$ and haloperidol decanoate/haloperidol $(\mathrm{N}=113,3 \%)$. Dual medications of long acting flupentixol decanoate with clozapine should be avoided (Drew et al. 2010).

Among the long acting antipsychotics three combinations were prescribed concomitantly: flupenthixol decanoate and fluphenazine decanoate were prescribed together twice. This is an unacceptable result as it is assumed that two long acting antipsychotics should not be prescribed concomitantly (Stahl 2009).

During the research period, we did not interfere with the psychiatrist's decisions. Although the national guidelines for the treatment of patients with schizophrenia are now quite old (Kocmur et al. 2000), psychiatrists use also other international guidelines, including the very recent ones. In general, the authors assume that prescribing practices, described in this research, do not depart significantly from current treatment guidelines for patients with schizophrenia. However, there are still several possible improvements. One of them is the use of recommended daily doses of antipsychotics in cases where prescribed doses were too low. The once quite frequent practice of prescribing very large doses of antipsychotic medications, well over the recommended dosing ranges, is nowadays very rare, probably also due to Mental Health Act which limits the use of doses above recommended range. Psychiatrists are expected to be knowledgeable of psychotropic drug interactions, but we recorded a lot of combinations of medications (also psychotropic) which should be avoided. With the knowledge about drug (interactions, adverse reactions, dosage, modes of admission) the implementation of clinical pharmacy services to the psychiatrists would significantly improve medication of inpatients with psychotic disorders and polypharmacotherapy.

\section{CONCLUSIONS}

For the first time in Slovenia, we provided a detailed overview of the prescribing patterns for inpatients with SSD. It was conclude that the medication in PBI is not optimal for at least few reasons. First, inpatients were exposed to a large number of different drugs. Second, there was a high risk for clinically relevant drug interactions because of polypharmacotherapy, especially with psychotropic drugs. Finally, the majority of inpatients received more than one antipsychotic at the same time and nine out of sixteen antipsychotics were prescribed in too low doses.

The results of the research indicated that additional measures are needed to improve medication. The inclusion of a clinical pharmacist in the process of drug treatment is one of the most efficient solutions. Positive outcomes such as significant improvement in clinical response and drug-induced extrapyramidal symptoms together with high satisfaction with the clinical pharmacy services are well documented (Canales et al. 2001). Moreover, a well-designed prospective research will have to be conducted as the key to successful improvement of drug therapy in psychiatric inpatient.

Psychiatrists and specialist in internal medicine at the PBI are now able to consult on the use of medications by a clinical pharmacist. This is particularly important for inpatients with polypharmacotherapy also with psychotropics, comorbidity, liver and/or kidney diseases, pregnant women and elderly.

\section{Acknowledgements:}

The authors would like to express their thanks to the management of $\mathrm{PBI}$ for all the support in conducting the research.

\section{Conflict of interest: None to declare.}

\section{Contribution of individual authors:}

Cvetka Bačar Bole: design of the study, literature searcher and analyses and interpretation of data;

Mitja Pišlar: statistical analyses;

Aleš Mrhar and Rok Tavčar: design of the study, literature searchers and analyses and interpretation of data. 


\section{References}

1. Barnes TR: Evidence-based guidelines for the pharmacological treatment of schizophrenia: recommendations from the British Association for Psychopharmacology. J Psychopharmacol 2011; 25:567-620.

2. Bolcato J, Terrazzani G, Giusti P, Walley T, Chinellato A: Atypical antipsychotic prescribing patterns in an Italian district 2001-2009 and the impact of regulatory warnings. Open Sci J Clin Med 2014; 2:10-4.

3. Canales PL, Dorson PG, Crismon ML: Outcomes assessment of clinical pharmacy services in a psychiatric inpatient setting. Am J Health Syst Pharm 2001; 58:1309-16.

4. Chong MY, Tan CH, Shinfuku N, et al.: Prescribing antipsychotic drugs for inpatients with schizophrenia in Asia: Comparison of REAP-2001 and REAP-2004 studies. Asia-Pac Psychiat 2010; 2:77-84.

5. Covell NH, Jackson CT \& Weissman EM: Health monitoring for patients who have schizophrenia. Summary of the Mount Sinai Conference recommendations. Postgrad Med 2006; Spec No:20-26.

6. Davids E, Bunk C, Specka M, Gastpar M: Psychotropic drug prescription in a psychiatric university hospital in Germany. Progress in Neuro-Psychopharmacology \& Biological Psychiatry 2006; 30:1109-1116.

7. De Hert $M$, van Eyck D, De Nayer A: Metabolic abnormalities associated with second generation antipsychotics. fact or fiction? Development of guidelines for screening and monitoring. Int Clin Psychopharmacol 2006; 21(Suppl 2):11-5.

8. Drew BJ, Ackerman MJ, Funk M, et al.: Prevention of Torsade de Pointes in Hospital Settings: A Scientific Statement from the American Heart Association and the American College of Cardiology Foundation. J Am Coll Cardiol 2010; 55:934-47.

9. Hasan A, Falkai P, Wobrock T, et al.: World Federation of Societies of Biological Psychiatry (WFSBP) Guidelines for Biological Treatment of Schizophrenia, part 1: update 2012 on the acute treatment of schizophrenia and the management of treatment resistance. W J Biol Psych 2012; 13:318-78.

10. Hennekens CH, Hennekens AR, Hollar D, Casey DE: Schizophrenia and increased risks of cardiovascular disease. Am Heart J 2005; 150: 1115-21.
11. Jordanova V, Maric NP, Alikaj V, et al.: Prescribing practices in psychiatric hospitals in Eastern Europe. European Psychiatry 2011; 26:414-418.

12. Kocmur M, Tavčar R, Žmitek A: Shizofrenija: priporočila in smernice za zdravljenje z zdravili. Viceversa. Ljubljana: Republiški strokovni kolegij za psihiatrijo, 2000.

13. Lehman AF, Lieberman JA, Dixon LB, et al.: Practice guideline for the treatment of patients with schizophrenia, second edition. Am J Psychiatry 2004; 161:1-56.

14. Matei VP, Mihailescu AI \& Davidson M: Is non-pharmacological treatment an option for certain schizophrenia patients? Psychiatr Danub 2014; 26:308-13.

15. Newcomer JW \& Haupt DW: The metabolic effects of antipsychotic medications. Can J Psychiatry 2006; 51:480-91.

16. O'Brien CP: Benzodiazepine use, abuse, and dependence. J Clin Psychiatry 2005; 66:(Suppl 2):28-33.

17. Pakpoor J, Agius M: A review of the adverse side effects associated with antipsychotics as related to their efficacy. Psychiatr Danub 2014; 26(Suppl 1):273-84.

18. Rittmannsberger H, Meise U, Schauflinger K, et al.: Polypharmacy in psychiatric treatment. Patterns of psychotropic drug use in Austrian psychiatric clinics. Eur Psychiatry 1999; 17:1-8.

19. Stahl SM: Essential psychopharmacology: the prescriber's guide. New York: Cambridge University Press, 2009.

20. Stein-Parbury J, Reid K, Smith N, et al.: Use of pro re nata medications in acute inpatient care. Australian and New Zeland Journal of Psychiatry 2008; 42:283-292.

21. Stockley IH: Stockley's Drugs Interactions. London: Pharmaceutical Press, 2002.

22. Sweetman SC: Martindale: the complete drug reference. 35th ed. London: Pharmaceutical Press, 2007.

23. Szkultecka-Dębek M, Miernik K, Stelmachowski J, Jakovljević M, Jukić V, Aadamsoo K, Janno S, Bitter I, Tolna J, Jarema M, Jankovic S, Pecenak J, Vavrusova L, Tavčar $R$, Walczak J, Talbot D \& Augustyńska J: Treatment patterns of schizophrenia based on the data from seven Central and Eastern European countries. Psychiatr Danub 2016; 28:234-42.

24. Weiden PJ, Aquila R, Emanuel M, Zygmunt A: Long-term considerations after switching antipsychotics. $J$ Clin Psychiatry 1998; 59(Suppl 19):36-49.

Correspondence:

Cvetka Bačar Bole, MPharm, Specialist in clinical pharmacy

Psychiatric Hospital Idrija

Pot sv. Antona 49, SI-5280 Idrija, Slovenia

E-mail: cvetka.bole@gmail.com; cvetka.bacar@pb-idrija.si 